PAPERS

\title{
Efficient fault identification scheme of compensated transmission grid based on correlated reactive power measurements and discrete wavelet transform
}

\author{
Mohamed I. Zaki ${ }^{1, *}$, Ragab A. El-Sehiemy ${ }^{2 *}$, Ghada M. Amer ${ }^{1}$
}

\begin{abstract}
The early fault identification in high-voltage power systems is a substantial aspect not only to minimize equipment failure but also to increase both the reliability and stability in power system. Subsequently, the aim of this paper is to propose the adaptive fault-identification scheme based on multi-resolution analysis technique. The proposed method is dependent on monitoring both voltages and currents from single-ended measuring system. The correlation among the reactive power computation and discrete wavelet transform is used to generate the significant criteria which are used to discriminate between short-circuit currents and energizing heavy loads behaviour. Different transmission network configurations are investigated to assess the dependability, security, and reliability of fault identification relay as well. The correlative protection scheme attains the accurate results under healthy disturbances, and therefore it is superior to other conventional approaches. In addition, a selective study is applied to different mother wavelets to find the best one. The response of the proposed scheme to the compensated transmission line is also verified at a wide range of compensation levels with faults before and after compensated bank. Simulation tests have been handled via ATP-EMTP to investigate the proper practicability and adaptability of the fault-identication relay.

K e y w or d s: compensated transmission lines, DWT, fault identification
\end{abstract}

\section{Introduction}

Fault detection and classification algorithms have a noticeable role to protect rise-cost and safety-critical high voltage power systems. With growing demands for electrical consumption, utilities are compelled to boost the transmission capability of electrical transmission systems. This is why immediately detection and classification process for short-circuit faults is required to protect transmission lines. In electrical power systems, there are many practical applications such as power transformers, induction motors, synchronous generators, transmission lines, and distribution systems, all these components need to bypass an abnormal event progression. Therefore, plenty of methods have been developed to deal with the fault detection issues through transmission networks. Nevertheless, these methods faced a lot of difficulties whether in discriminating heavy load switching or in recognizing a little transmission line faults [1-2]. As an illustration, in the case of heavy load switching (non-fault) occurrence, the behaviour of three phases currents and voltages may resemble a three-phase fault situation which is more likely to lead to wrong decision. Thus, conventional schemes require more developing to increase their ability to distinguish heavy load switching conditions and three-phase fault cases. In fact, the mal-operation of pro- tective relaying systemswhich have been designed to detect, classify, identify faulty phase, and remove the fault eventsmay cause the catastrophic effects on power system networks [3]. Therefore, the accurate fault detection and classification actions must be proposed to perform the speedy recovery of the unhealthy phases and to decline the time abruption. In reality, transmission lines confront a considerable rise in electromagnetic transient signals through cables while short circuit occurrence. These phenomena constitute non-stationary signal through transmission lines in both time and frequency domains. A DWT based- multi-resolution analysis technique (MRAT) is one of the most outstanding methods to analyze these non-stationary signals in which it markedly provides detailed information about faults to protection main purpose [4]. A MRAT has the capability of capturing the relevant features of elevtrical signals and localize them in time-domain precisely. The extracted feature from measured signals aids to identify the natural of faults so that more and more attempts have been addressed in fault-identification area for either compensated and non-compensated transmission lines. To begin with non-compensated transmission lines, many studies have been introduced to detect and classify faults without using any intelligent system [5-8]. The proposed schemes used DWT to obtain and extract the salient features of

\footnotetext{
${ }^{1}$ Electrical Engineering Department, Faculty of Engineering, Benha University, Egypt, ${ }^{2}$ Electrical Engineering Department, Faculty of Engineering, Kafrelsheikh University, Egypt, * corresponding author: elsehiemy@eng.kfs.edu.eg
}

https://doi.org/10.2478/jee-2021-0031, Print (till 2015) ISSN 1335-3632, On-line ISSN 1339-309X

(C) This is an open access article licensed under the Creative Commons Attribution-NonCommercial-NoDerivs License (http: //creativecommons.org/licenses/by-nc-nd/3.0/). 
the faulty signals. In [9-10], the merging of DWT, Singular Value Decomposition (SVD) and Shannon entropy was presented to identify fault distinctive in transmission network. Reference [11] proposed the fault identification scheme for three-terminal transmission systems via monitoring the impact of reactive power behaviour during fault condition. In [12], new terminologies in fault identification process were suggested namely, the sensitivity and stability of fault identification schemes. This study also relied on the DWT by using the hybridization among wavelet coefficients and their deviation corresponding to three-phase currents. In [13-20], other methods were suggested by using of the artificial neural-networks (ANNs) and / or expert systems. In [13], an algorithm relied on the conjunction of DWT and ANNs technique for a fault identification was addressed. In [14], a novel method was performed using hyperbolic s-transform based on radial basis function neural-network (RBFNN) for a fault classification concept. Also, in [15], a new method was derived using integrated multi-wavelet packet entropy technique with RBFNN for classifying of different fault types. In [16], a developed fault-identification algorithm relied on the combination of both DWT and Probability Neural Network (PNN) to extract the distinctive fault features was introduced. In [17], the short-circuit fault was identified via the intrinsic time decomposition technique based on the integration of Singular Value Decomposition (SVD) with PNN. In [18], a protection scheme for a tripled-circuits transmission line was proposed by using the incorporation of DWT and Deep Neural Network (DNN) in which the DNN is trained using wavelet coefficients of current signals. In [19], the performance of fault identification relay (FIR) based on the machine intelligent platform WEKA via the integration of three types of selection techniques, namely information gain, gain ratio and support vector machine (SVM) algorithms were applied to doubled-circuits transmission line. The determinant function was inferred and used to extract the salient fault features over different data windows. In [20], a method relied on SVM technique was presented. This scheme was mainly dependent on DWT to handle the important features for fault detection process. These features were then fed into SVM technique to identify the unhealthy phases. However, the negative side of ANN \& expert systems are relying on huge samples and data of training for the picture of perception, which greatly defects their practical applications. Also, most studies have been unable to assimilate transmission line uncertainties that may impact on the reliability of FIR.

As for a series-compensated transmission line, a great number of FIRs suffer from the mal-operation of fault identification schemes at various conditions. As a matter of fact, the series compensator is constructed by both metal oxide varistor MOV and parallel air-gap combination to enhance voltage profile and transmission capability, but this combination results in a rise in system nonlinearity. For this reason, the series compensated transmission line configurations is not straightforward and requires advanced protection algorithms. On top of that, the most recent publications related to fault identification schemes based on both series- and shunt- compensation have been introduced in [21-26]. In [21], a review in the protection schemes regarding series compensated networks was presented. The core of this work was to delineate the most popular types of series compensation-based fault identification complexities which have been founded in power system. In [22], based on distributed parameter model, the fault location scheme was presented via monitoring unsynchronized voltage and current signals for a series- compensated line. In [23], an integrated directional relay method was presented to a series compensated line. The proposed scheme relied on the use of the measured phase angle and magnitude of the positive-sequence current and voltage, respectively. The discrimination among transient and permanent faults was introduced for transmission line including shunt compensated reactors in [24]. In [25], another reclosing scheme was presented for shunt reactor compensated systems on the basis of current spectrum analysis. In [26], an adaptive neuro-fuzzy inference system (ANFIS) was developed for fault recognition process in the presence of series compensated transmission line. It is found that most conventional FIRs in previous studies are inadequate to provide the corrective decision with a wide range of compensation levels. Also, many of them consisted of multi-stage techniques. This inevitably leads to consume more time and increase their computational burden. To redress these gaps, in this paper, a proposed adaptive fault-identification scheme (AFIS) is designed to overcome this dilemma relying on the integration of instantaneous reactive power with MRAT. Based on this integration, the proposed scheme can identify the short-circuit fault on compensated transmission network; meanwhile, the complication of discriminating among heavy load switching and short-circuit fault could be solved. The proposed scheme depends on real -time currents and voltages captured from one side of transmission line through the sliding window to compute instantaneous reactive power which processed via DWT to extract fault criteria. As a result, the proposed AFIS based the wavelet coefficients relied on the reactive power behaviour during disturbance that provides faster and more accurate fault-identification action than well-known wavelet coefficients based only on voltages or currents as reported in previous works. A 6.4-kHZ sampling rate and db6 mother wavelet are selected to make a little of computational attempts. The performance of the proposed method is tested and evaluated under different healthy and unhealthy disturbances with different short-circuit parameters. In addition, both dependability and security concepts would be discussed to evaluate the performance of AFIS. Using the integrating of ATP-EMTP and MATLAB simulators, the results are presented to illustrate the potential benefits of the proposed AFIS.

We provide an overview of reactive power computation with the basic concepts of conventional wavelet transform. The proposed scheme of fault identification relay is 


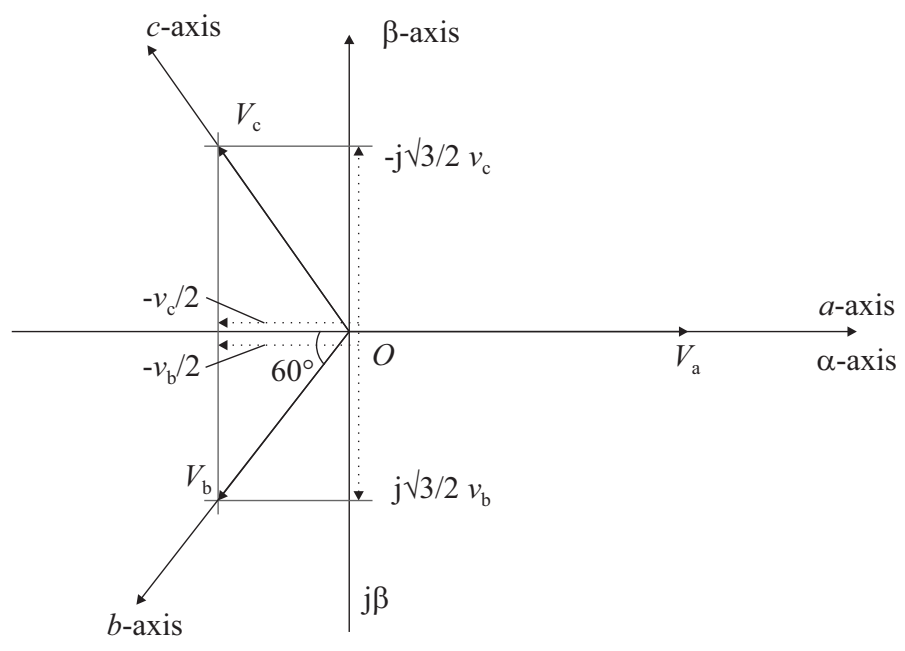

Fig. 1. The conversion of three phases coordinates $\mathrm{ABC}$ to $\alpha$ and $\beta$ coordinates

presented and the tested transmission network is simulated with different fault cases. The result of fault identification scheme is discussed and its dependably factors are presented together with an assessment study of proposed scheme compared to the most closed schemes in literature.

\section{Reactive power computation and DWT analysis}

\subsection{The instantaneous reactive power computation}

The dependency of previous fault identification techniques on the currents and voltages nature is not accurate because the power system performance (e.g. load, switching) may change continuously. For this, a new approach based on the reactive power attitude is introduced in this proposed method. The application of reactive power-fault identification studies is implemented using Clarke model. It is well-known that the Clarke transformation is often applied to analyze an imbalanced grid during fault occurrence [27]. First of all, the three phase voltages and currents are converted to two orthogonal stationary axes which are denoted as $\alpha$-axis and $\beta$-axis, each of them is perpendicular to each other. The Clarke transformation for three phases voltage coordinates $\mathrm{ABC}$ is depicted as Fig. 1.

The phase-model transformation of instantaneous voltages can be derived as follows

$$
\left[\begin{array}{c}
v_{0} \\
v_{\alpha} \\
v_{\beta}
\end{array}\right]=\sqrt{\frac{2}{3}}\left[\begin{array}{ccc}
\frac{1}{\sqrt{2}} & \frac{1}{\sqrt{2}} & \frac{1}{\sqrt{2}} \\
1 & -\frac{1}{2} & -\frac{1}{2} \\
0 & \frac{\sqrt{3}}{2} & -\frac{\sqrt{3}}{2}
\end{array}\right] \cdot\left[\begin{array}{c}
v_{\mathrm{a}} \\
v_{\mathrm{b}} \\
v_{\mathrm{c}}
\end{array}\right]
$$

where $v_{\mathrm{a}}, v_{\mathrm{b}}, v_{\mathrm{c}}$ are, respectively, instantaneous voltage corresponding to three phases and $v_{\alpha}, v_{\beta}$ refer to sta- tionary orthogonal of voltages, and $v_{0}$ refer to voltage ground mode, therefore,

$$
\begin{gathered}
v_{0}=\frac{1}{\sqrt{3}}\left(v_{\mathrm{a}}+v_{\mathrm{b}}+v_{\mathrm{c}}\right), \\
v_{\alpha}=\sqrt{\frac{2}{3}}\left(v_{\mathrm{a}}-\frac{v_{\mathrm{b}}}{2}-\frac{v_{\mathrm{c}}}{2}\right), \\
v_{\beta}=\frac{1}{\sqrt{2}}\left(v_{\mathrm{b}}-v_{\mathrm{c}}\right) .
\end{gathered}
$$

Similarly, we can derive the Clarke transformation of instantaneous three phase currents $i_{\mathrm{a}}, i_{\mathrm{b}}$, and $i_{\mathrm{c}}$, which is given below to extract $i_{0}, i_{\alpha}$, and $i_{\beta}$.

$$
\left[\begin{array}{c}
i_{0} \\
v_{\alpha} \\
v_{\beta}
\end{array}\right]=\sqrt{\frac{2}{3}}\left[\begin{array}{ccc}
\frac{1}{\sqrt{2}} & \frac{1}{\sqrt{2}} & \frac{1}{\sqrt{2}} \\
1 & -\frac{1}{2} & -\frac{1}{2} \\
0 & \frac{\sqrt{3}}{2} & -\frac{\sqrt{3}}{2}
\end{array}\right] \cdot\left[\begin{array}{c}
i_{\mathrm{a}} \\
i_{\mathrm{b}} \\
i_{\mathrm{c}}
\end{array}\right],
$$

where, $i_{\alpha}, i_{\beta}$ refer to stationary orthogonal of currents, and $i_{0}$ refers to ground current mode.

Based on Clarke transformation, the instantaneous reactive power $q(t)$ is computed as the cross product of two mutual perpendicular quantities as mentioned in [27]. The calculation of instantaneous reactive power is expressed as,

$$
q(t)=v_{\alpha} i_{\beta}-v_{\beta} i_{\alpha}
$$

Therefore, the instantaneous reactive power measured per phase can be represented as

$$
\begin{aligned}
& q_{\mathrm{a}}(t)=\frac{1}{\sqrt{3}}\left(v_{\mathrm{c}}-v_{\mathrm{b}}\right) i_{\mathrm{a}}, \\
& q_{\mathrm{a}}(t)=\frac{1}{\sqrt{3}}\left(v_{\mathrm{a}}-v_{\mathrm{c}}\right) i_{\mathrm{b}}, \\
& q_{\mathrm{a}}(t)=\frac{1}{\sqrt{3}}\left(v_{\mathrm{b}}-v_{\mathrm{a}}\right) i_{\mathrm{c}},
\end{aligned}
$$

where, $q_{\mathrm{a}}(t), q_{\mathrm{b}}(t)$, and $q_{\mathrm{c}}(t)$ are the measured reactive power corresponding to three phases $(a, b, c)$ at relay point. 


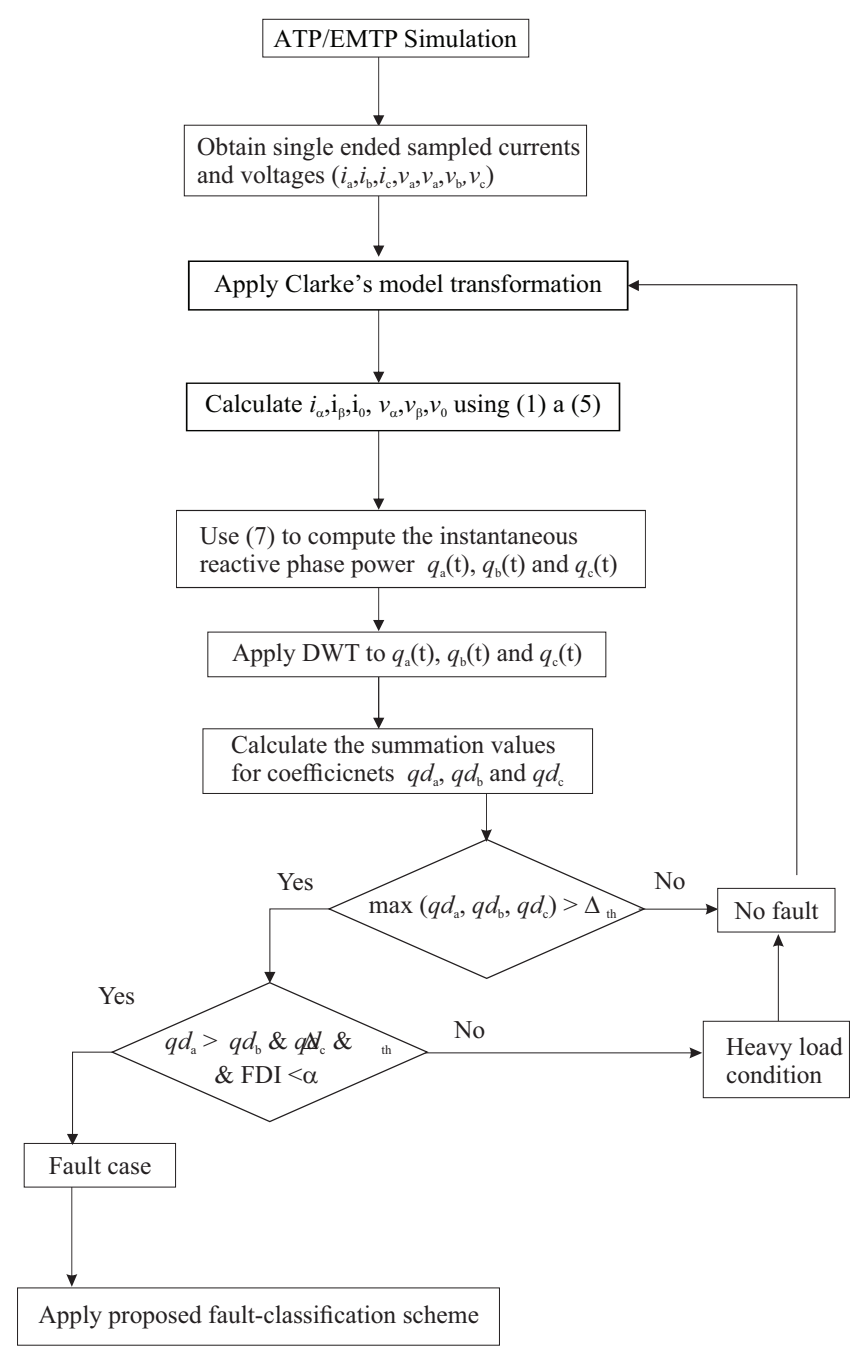

Fig. 2. Flow chart for proposed fault detection scheme

\subsection{Extraction of wavelet coefficients-based signal pro- cessing technique}

The DWT-based multi-resolution analysis technique possesses better properties than conventional DFT. The DWT has extracted more detailed information about both time and frequency domains. Wavelet technique is the most perfect decomposition tool that is used to extract the salient features of transmission line faults. Consequently, following that the instantaneous reactive power per phase is calculating, the MRAT is applied to decompose the computed reactive power signals into details and approximate coefficients. DWT is designed to give details and approximate coefficients for input signals as tree-structured filter bank as follows [28]

$$
\begin{aligned}
& A_{1}[k]=\sum_{n=-\infty}^{\infty} X[n] L[n-2 k], \\
& D_{1}[k]=\sum_{n=-\infty}^{\infty} X[n] h[n-2 k],
\end{aligned}
$$

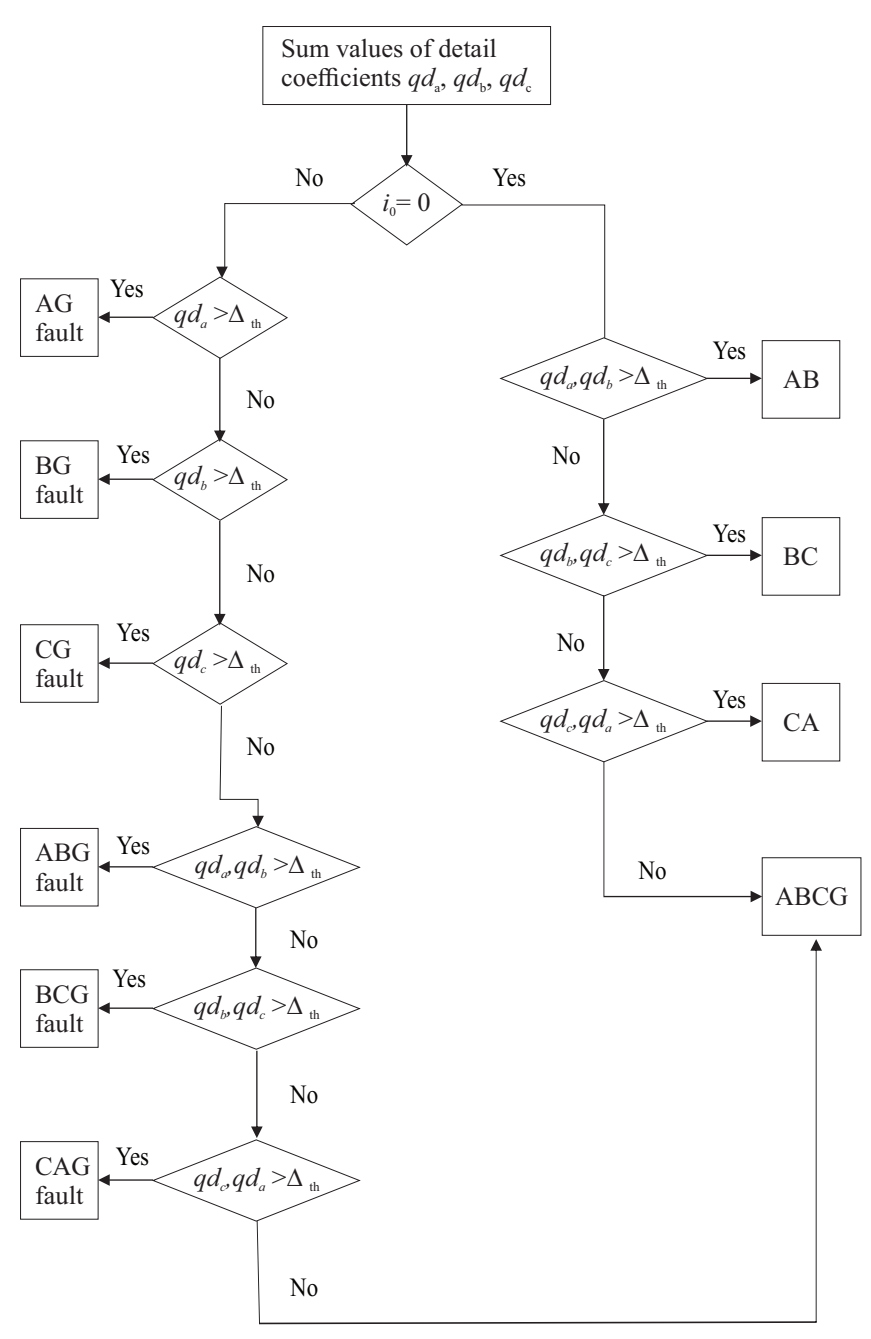

Fig. 3. Flow chart for proposed fault classification scheme

where, $X$ is the input sampled signal, $k$ represents the translation interval, $L(n)$ and $h(n)$ are scaling and wavelet filters. The reactive power details are relied on translating and dilating of fixed basis function, namely, mother wavelet. A basis wavelet function is defined as below, [28]

$$
\Psi_{j, k}(t)=2^{-j / 2} \Psi\left(2^{-j} t-k\right)
$$

The mother wavelet selection represents a critical aspect in fault detection and classification techniques because the high-frequency components are highly affected to mother wavelet choice. The Daubechies wavelet family is adopted in this study. As a matter of fact, it is more sensitive to sudden changes as fault and heavy load switching [29]. Therefore, the db6 is selected as mother wavelet to decompose the measured reactive power signals into high- and low-frequency components. The proposed method founds that db6 (mother wavelet) has ability to give a high performance based on reactive power 
measurements. Meanwhile, the sum value of details coefficients per phase (SVDCs) are computed and used as criterion for fault detection and classification scheme. Also, the details coefficient of ground current mode is used to differentiate among grounded and ungrounded faults.

\section{Proposed reactive power measurements based protection scheme}

In this study, the proposed AFIS relied on local voltages and currents are only captured from one-terminal measuring system. Next, three-phase voltages and currents are sampled at sampling rate $\left(f_{\mathrm{s}}=6.4 \mathrm{kHz}\right)$ as in [6]. The Clarkes model transformation is applied to sampled signals as illustrated through (1) to (5). Subsequently, the instantaneous reactive powers per phase are calculated corresponding to (7)-(11) as mentioned in section 2. Thereafter, the MRAT combined through one-level of decomposition is presented to extract the details of reactive power. Finally, the SVDC for each phase $\left(q d_{\mathrm{a}}, q d_{\mathrm{b}}, q d_{\mathrm{c}}\right)$ is used as input to the proposed protection scheme. The proposed scheme is implemented in two subsequent stages. In the first stage, the term of Fault Detection Index (FDI) based on SVDC is proposed. The FDI is designed to discriminate between fault situation and heavy load switching. In the second stage, after the fault would be discriminated, the same input data are utilized to make fault classification process.

\subsection{Fault detection based reactive-power computation}

The proposed fault-detection scheme is designed to be able to detect any type of shunt-fault as well as making discrimination between non-fault transient events. Due to the proposed FDI, the fault-detection scheme can overcome the major issue in the previous studies. To put it differently, most of existing studies could be detect any heavy load switching event like a symmetrical fault rather than non-fault transient event. Consequently, the proposed fault-detection scheme is designed to combat this issue. Based on indices are defined as the SVDC, the proposed scheme works with high effective and reliable operation. Generally speaking, under normal operation, the values of $q d_{\mathrm{a}}, q d_{\mathrm{b}}$, and $q d_{\mathrm{c}}$ have marginal changes. By comparing the maximum term of $q d_{\mathrm{a}}, q d_{\mathrm{b}}, q d_{\mathrm{c}}$ values with an adaptive threshold value, the heavy load switching, or transmission line fault can be detectable. With this in mind, if the maximum value of sum details per phase exceeds an adaptive threshold value $(\Delta t h)$ and FDI is less than a fixed threshold value (), the fault is detected. On the contrary, provided that the SVDC for all phases exceeds over the adaptive threshold value and FDI is higher than the fixed threshold value, the non-fault transient event is detected as a result the proposed scheme does not react. The proposed FDI is defined as the ratio of difference maximum and minimum sum of details per phase to median sum of details value as follows

$$
F D I=\frac{\max \left(q d_{i}\right)-\min \left(q d_{i}\right)}{\operatorname{med}\left(q d_{i}\right)}, \quad i=\mathrm{a}, \mathrm{b}, \mathrm{c} .
$$

where, $q d_{i}$ sum of details per phase, min, max, and mid refer to the minimum, maximum, median values, respectively. The adaptive-threshold is defined as the logical pattern as the following formula

$$
\Delta_{\mathrm{th}}=\max \left(q d_{\mathrm{a}}, q d_{\mathrm{b}}, q d_{\mathrm{c}}\right) \varepsilon
$$

where qda, qdb, qdc are SVDC for phase A, B, and C, respectively. In this equation, the parameter $\Delta_{\text {th }}$ denotes the adaptive threshold. Further, the adaptive threshold value needs to the correction index which is required to make a corrective decision that is denoted as $\varepsilon$. This threshold value is adaptively relied on the transmission line topologies as well as diverse loading conditions and source impedance variations. It must be mentioned that the choice of adaptive threshold value for fault detection schemes is a critical aspect. For this reason, a straightforward method named Otsu thresholding method is considered to set the adaptive threshold. Figure 2 illustrates the flow chart diagram of the presented fault-detection method based on a logical pattern using adaptive threshold and FDI.

\subsection{Fault classification based reactive-power computa- tion}

After a fault detection is declared, it is a very important to identify which type of fault has taken place, once the data are reached to protective relay. The proposed reactive power- based fault classification scheme is performed using the SVDC in each phase. This criterion is used to classify between different fault types based on the proposed adaptive threshold formula as (13). In this study, the same features which have been extracted in the detection stage are also used in classification scheme. Forthwith, the fault detection is investigated, the faulty phase will be identified using another logical pattern as depicted in Fig. 3. The flowchart describes the entire features of the proposed fault-classification scheme. The classification methodology is launched using the value of $q d_{\mathrm{a}}, q d_{\mathrm{b}}, q d_{\mathrm{c}}$ and ground current mode value which is able to discriminate between grounded and ungrounded faults. For instance, during single phase to ground fault, the SVDC of faulty phase only exceeds the adaptive $\Delta_{\text {th }}$, whereas double phase to ground fault, the SVDCs of faulty phases exceed the adaptive $\Delta_{\text {th }}$, this means that the SVDC in faulty phase is higher than the healthy phase. For three-phase fault, the values of $q d_{\mathrm{a}}, q d_{\mathrm{b}}, q d_{\mathrm{c}}$ exceed the adaptive $\Delta_{\text {th }}$ threshold value. 


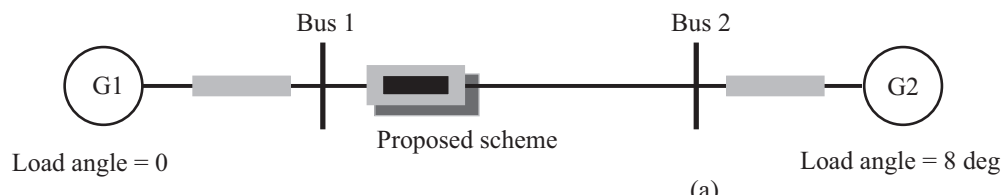

(a)

(a)
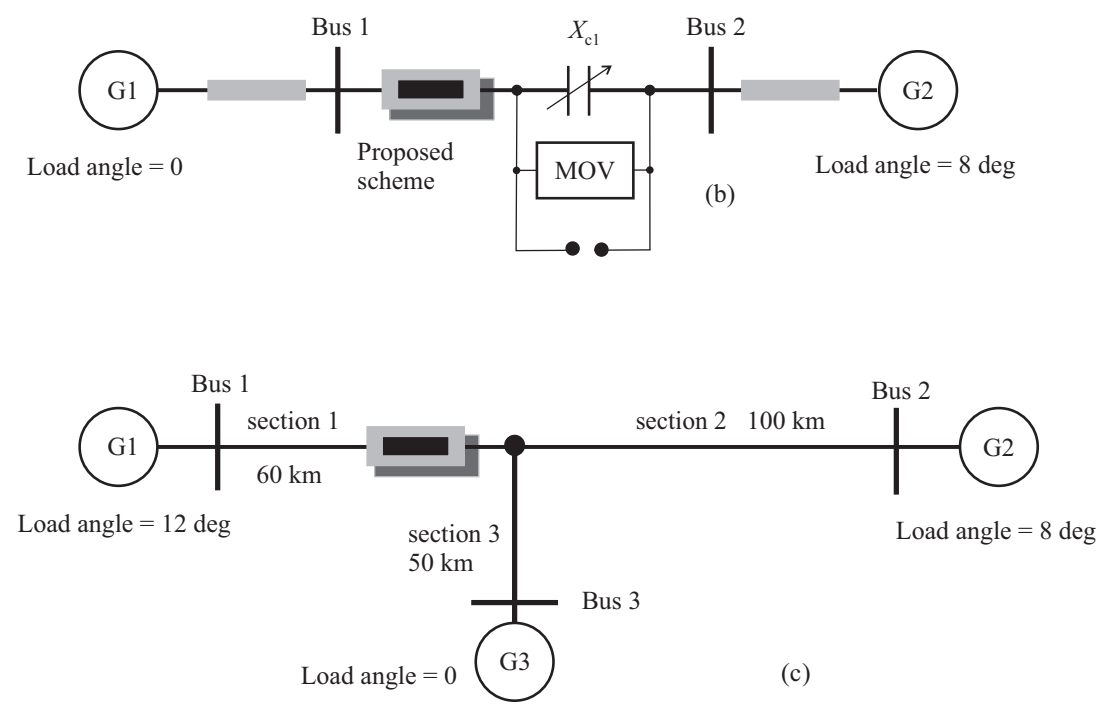

Fig. 4. Studied different transmission network configurations: (a) - uncompensated two-terminal networks, (b) - compensated twoterminal networks, and (c) - teed transmission lines

\section{Applications}

\subsection{Description of studied different transmission net- work configurations}

To check the reliability of the proposed method, different transmission network configurations have been simulated via ATP/EMTP package. The first one is a typical $500 \mathrm{kV}$ uncompensated two-terminal transmission lines, $50 \mathrm{~Hz}$, is used to test the proposed method performance. Two-sources are interconnected by using single overhead transmission lines and its length is $300-\mathrm{km}$ as shown in Fig. 4(a). The data of the tested system for substations and transmission line are mentioned in [7]. The second one is a typical $500-\mathrm{kV}$ series-compensated two-terminal transmission lines. Series-compensated line is investigated by inserting series capacitors at midpoint of a two-terminal transmission line to alleviate the impact of inductive reactance and enhance the system load ability. As depicted in Fig. 4(b), Metal oxide varistor (MOV) and air gab unit have been used to protect the series capacitor against surge high voltage during abnormal situation. The information of compensated transmission line model is taken as [23]. The last one is a typical $400-\mathrm{kV}$, $50 \mathrm{~Hz}$, teed transmission lines as shown in Fig. 4(c). The teed system has three branches (sec1, sec2, and sec3) and their lengths are $60 \mathrm{~km}, 100 \mathrm{~km}, 50 \mathrm{~km}$, respectively. The test transmission line parameters and sources information are provided as in [30].

\subsection{Fault simulation studies}

Several simulations studies have been verified for all studied transmission network configurations as depicted in Fig. 4. when fault occurs, voltages and currents are sampled from single end measuring system. The simulation provides sampled signals at a frequency of $6.4 \mathrm{kHz}$ (128 samples / cycle) to the scheme. From ATP -EMTP simulator, all through one cycle window, sampled voltages and currents are loaded into the MATLAB program. Thereafter, the reactive powers are computed and then they are processed via MRAT, following that the fault criteria are fed into the proposed method to discriminate between fault and heavy load switching condition. Finally, the fault classification is presented to recognize the faulty phase. For this purpose, several fault cases and heavy loads switching have been tested to show the success of the proposed method.

- Single phase to ground fault (AG, BG, CG)

- Double phase to ground fault (AB-G, BC-G, CA-G)

- Double phase to phase fault (A-B, B-C, C-A)

- 3-phase fault (ABC-G)

The proposed method also has been studied at different fault parameters eg resistances, locations and inception angles to verify the authenticity of the proposed scheme. 
Table 1. Simulation studies for selecting the convenient mother wavelet

\begin{tabular}{|c|c|c|c|c|c|c|}
\hline $\begin{array}{l}\text { Fault } \\
\text { type }\end{array}$ & $\begin{array}{l}R_{\mathrm{F}} \\
(\Omega)\end{array}$ & $\begin{array}{c}q d_{\mathrm{a}} \\
\times 10^{3}\end{array}$ & $\begin{array}{l}q d_{\mathrm{b}} \\
\times 10^{3}\end{array}$ & $\begin{array}{c}q d_{\mathrm{c}} \\
\times 10^{3}\end{array}$ & $\begin{array}{c}i_{0} \\
(\mathrm{~A})\end{array}$ & $\begin{array}{c}\text { Fault identification } \\
\text { Decision }\end{array}$ \\
\hline & & & $\mathrm{db} 4$ & & & \\
\hline Healthy & & 246.3 & 232 & 248.87 & 0 & No-fault \\
\hline LG & 0.001 & 5641.9 & 255 & 294.23 & 390 & $\mathrm{LG}$ \\
\hline LLG & 60 & 1804.8 & 2083 & 298.15 & 174 & LLG \\
\hline LL & 80 & 1908.8 & 2608 & 159.16 & 0 & False decision \\
\hline \multirow[t]{2}{*}{ LLL } & 200 & 702.9 & 681 & 662.7 & 0 & False decision \\
\hline & & & db6 & & & \\
\hline Healthy & & 2.02 & 2.15 & 2.18 & 0 & No-fault \\
\hline LG & 0.001 & 48.18 & 2.22 & 2.69 & 390 & LG \\
\hline LLG & 60 & 15.91 & 17.72 & 2.56 & 147 & LLG \\
\hline LL & 80 & 16.83 & 22.95 & 1.42 & 0 & $\mathrm{LL}$ \\
\hline \multirow[t]{2}{*}{ LLL } & 200 & 6.23 & 5.847 & 5.92 & 0 & LLL \\
\hline & & & $\mathrm{db} 8$ & & & \\
\hline Healthy & & 0.19 & 0.171 & 0.189 & 0 & No-fault \\
\hline LG & 0.001 & 4.75 & 0.208 & 0.393 & 390 & LG \\
\hline LLG & 60 & 1.14 & 1.129 & 0.187 & 147 & LLG \\
\hline LL & 80 & 1.18 & 1.766 & 0.091 & 0 & False decision \\
\hline \multirow[t]{2}{*}{ LLL } & 200 & 0.48 & 0.589 & 0.443 & 0 & False decision \\
\hline & & & $\mathrm{db} 10$ & & & \\
\hline Healthy & & 0.19 & 0.162 & 0.168 & 0 & No-fault \\
\hline LG & 0.001 & 4.58 & 0.206 & 0.295 & 390 & LG \\
\hline LLG & 60 & 1.25 & 1.149 & 0.161 & 174 & LLG \\
\hline LL & 80 & 1.20 & 1.789 & 0.101 & 0 & LL \\
\hline LLL & 200 & 0.46 & 0.524 & 0.479 & 0 & False decision \\
\hline
\end{tabular}

\subsection{The appropriate selection for mother wavelet}

Different mother wavelets have been assessed to identify the convenient mother wavelet to a practical application. The choice of beneficial mother wavelet plays a significant aspect in application of fault detection and classification. There have been more previous studies that reported in recent decades with applicable impact of wavelet / wavelet packet transform for given application. The Daubechies (db) is commonly used as basis wavelet for protection purpose. Generally, db4 mother wavelet is used as the perfect method for fault detection. At the same time, the use of db6 mother wavelet has been suggested in [4], [29], and [31]. For the purpose of picking up the most acceptable basis wavelet, different mother wavelets are addressed as shown in Tab. 1 to verify of the selection of the most dominant mother wavelet corresponding to proposed scheme. The first system as shown in Fig. 4(a) is used to appraise the proposed scheme with using db6 as the more advantageous mother wavelet.

\section{Results and discussion}

\subsection{Assumptions}

To assess the optimum fault detection and classification algorithm, the majority of studies have been done in this paper. These studies revealed that the SVDCsbased reactive power measured per phase during fault condition are higher than healthy phases. On the other hand, during healthy condition, the SVDCs-based reactive power corresponding to three phases have no significant difference between them. With this evidence, this criterion is allocated as a discriminative feature in the proposed approach. An adaptive-threshold value is estimated according to the discriminative feature during healthy case based on sliding window technique. It was tested and investigated via the proposed scheme to show how the proposed AFIS can operate correctly under different operating conditions. For practical application, any FIR scheme in general for protection purpose requires adabtive method to prevent false tripping due to non-fault transient events. The reason for this is that protection schemes always need to set threshold values. Therefore, 
Table 2. The impact of series compensation on the proposed scheme and fault

\begin{tabular}{|c|c|c|c|c|c|c|c|c|c|}
\hline \multirow{2}{*}{$\begin{array}{l}\text { Compensation } \\
\text { percentage }\end{array}$} & \multirow{2}{*}{$\begin{array}{l}\text { Fault } \\
\text { type }\end{array}$} & \multirow[b]{2}{*}{$\begin{array}{c}d_{\mathrm{F}} \\
(\mathrm{km})\end{array}$} & \multirow[b]{2}{*}{$\begin{array}{l}R_{\mathrm{F}} \\
(\Omega)\end{array}$} & \multicolumn{5}{|c|}{ Coefficients and features } & \multirow[b]{2}{*}{ Relay decision } \\
\hline & & & & $\begin{array}{l}q d_{\mathrm{a}} \\
\times 10^{3}\end{array}$ & $\begin{array}{l}q d_{\mathrm{b}} \\
\times 10^{3}\end{array}$ & $\begin{array}{c}q d_{\mathrm{c}} \\
\times 10^{3}\end{array}$ & $\begin{array}{l}\Delta_{\text {th }} \\
\times 10^{3}\end{array}$ & $\begin{array}{l}i_{0} \\
(\mathrm{~A})\end{array}$ & \\
\hline & Healthy & & & 2.17 & 2.01 & 2.22 & & 0 & No-fault \\
\hline \multirow[t]{3}{*}{0} & LG & 50 & 100 & 15.32 & 2.25 & 2.01 & 3.25 & 129 & LG fault in phase $A$ \\
\hline & LG & 30 & 300 & 9.08 & 1.74 & 1.49 & & 64.82 & LG fault in phase \\
\hline & Healthy & & & 2.19 & 2.20 & 2.19 & & 0 & No-fault \\
\hline \multirow[t]{3}{*}{30} & LG & 50 & 100 & 15.98 & 2.27 & 2.01 & 3.21 & 129 & LG fault in phase \\
\hline & LG & 30 & 300 & 9.29 & 1.79 & 1.53 & & 64.82 & LG fault in phase \\
\hline & Healthy & & & 2.18 & 2.08 & 2.20 & & 0 & No-fault \\
\hline \multirow[t]{3}{*}{40} & LG & 50 & 100 & 15.64 & 2.24 & 2.08 & 3.20 & 129 & LG fault in phase \\
\hline & LG & 30 & 300 & 9.06 & 1.74 & 1.53 & & 64.82 & LG fault in phase \\
\hline & Healthy & & & 2.17 & 2.05 & 2.18 & & 0 & No-fault \\
\hline \multirow[t]{3}{*}{50} & LG & 50 & 100 & 16.00 & 2.25 & 2.18 & 3.19 & 129 & LG fault in phase \\
\hline & LG & 30 & 300 & 9.03 & 1.76 & 1.50 & & 64.82 & LG fault in phase \\
\hline & Healthy & & & 2.14 & 2.05 & 2.16 & & 0 & No-fault \\
\hline \multirow[t]{2}{*}{70} & LG & 50 & 100 & 15.86 & 2.27 & 2.01 & 3.14 & 129 & LG fault in phase \\
\hline & LG & 30 & 300 & 9.05 & 1.76 & 1.51 & & 64.82 & LG fault in phase \\
\hline
\end{tabular}

and could be used to identify short circuit fault. is the correction index with a range 1.09-1.2 for fault identification task, is fixed threshold value with range 0.18-0.25.

\subsection{Simulation results}

The response of the proposed AFIS has been tested on compensated transmission lines via series capacitor insertion at the middle of the line as shown in Fig. 4. It is well-known that the installed series-capacitor improves the power transfer capability of the line and enhances voltage profile. Furthermore, series compensation method is the way to inject the reactive power in series through the transmission line; as a result, it reduces the impedance of the line. The proposed scheme is tested under different levels of compensation as 30\%, 40\%, 50\%, and $70 \%$. The choice of these specific compensation levels is based on the existing studies as reported in $[21,25,26]$. Table 4 shows the performance of proposed scheme with \& without series compensation capacitor under healthy and faulty conditions. For healthy case, it is observed that the slight changing in adaptive threshold value between different compensation levels during healthy cases. During fault cases, in the case of compensated transmission line, the presence will alter the effective fault impedance. So, the conventional FIRs schemes have limitations in that case. Table 2 shows the simulation results for single line to ground fault before /after compensator bank. Also, the capacitor compensation level is varied a wide range from $30 \%$ to $70 \%$. It is cleared from several tests that the proposed scheme is able to detect and classify faults on series compensated lines correctly. To evaluate the effective of proposed scheme, diffident faults with varying resistances are simulated. Due to the increasing of faultresistance value, the fault current may be exposed to considerable damping in its magnitude. To prove the efficacy of the proposed fault-identification scheme against this difficulty, six different values of fault-resistances $\left(R_{F}=\right.$ $3,6,40,60,80,100,300 \Omega$ ) are simulated. Table 1 illustrates that the proposed scheme is immune to the effect of fault resistances in a wide range from $\left(R_{F}=0\right.$ to $\left.300 \Omega\right)$. Therefore, the proposed scheme can be still insensitive to high fault-resistance and can give a right response for the tested transmission configuration.

\section{Dependability and security of proposed AFIS}

The proposed AFIS is appraised using two significant characteristics: dependability and security. Basically, Basically, it is necessary that the multifunctional AFSI provides the protective relay including the capability to achieve both dependability and security without compromising either. In this case some false tripping may happen, which can lead in the worst-case to catastrophic impact on power system. In fact, the dependability indicates to a certainty grade that AFIS will run correctly, and this term is mainly dependent on the relay sensitivity. To demonstrate the performance of proposed AFIS, the dependability and security of the proposed scheme 

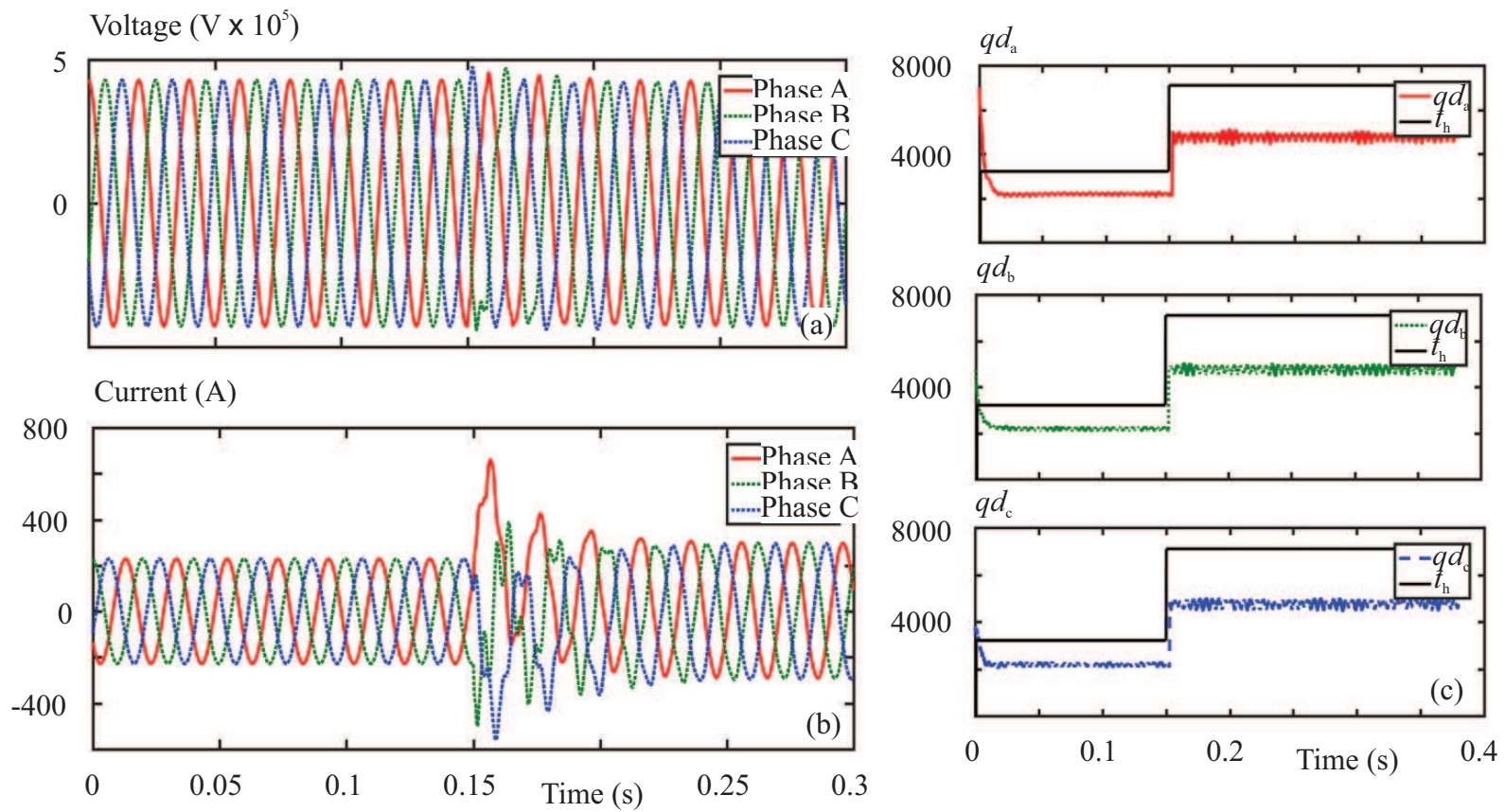

Fig. 5. The impact of load variation without faults: (a) - currents, (b) - voltages, and (c) - the behavior of SVDCs during load change

are measured as

$$
\begin{gathered}
\text { dependability }=\frac{\text { correct decisions }}{\text { desired decisions }} \times 100, \\
\text { security }=\frac{\text { correct decisions }}{\text { total decisions }} \times 100 .
\end{gathered}
$$

Considering all studied cases based on fault parameter variations, a total 1200 cases were simulated. The total number of corrective decisions was 1158 fault cases; therefore, the measured dependability of the proposed AFIS is $96.5 \%$. Meanwhile, the term of security is key feature in a protective relay in which it measures the certainty grade that the relay will not run incorrectly. Furthermore, the security term is mainly dependent on the relay selectivity. To clarify the performance of proposed AFIS based on the security term, the security formula is expressed by (18). As mentioned above the total number of corrective decisions was 1158 , but the aggregated fault decisions that the proposed AFIS reported including false decisions was 1188 . Therefore, the percentage of security for proposed AFIS is $97.4747 \%$. The AFIS has been investigated to compensated two-terminal transmission line with different compensating levels. Numerous healthy and unhealthy disturbances have been examined to prove the efficacy of the AFIS for different fault parameters. The results showed the ability of AFIS to identify short circuit fault and discriminate healthy disturbance (e.g., heavy load switching, source impedance variations, and loading change) correctly as in Fig. 5.

\section{Flexibility of proposed method against heavy load switching}

Most previous protection schemes under normal load condition can extremely operate well. In practice, the case of energizing heavy load may be occurred in electrical power grid, which leads to generate the transient prior to fault behaviour. Therefore, it is important to discriminate between heavy load and fault condition. Due to the fact that the energizing of heavy load is similar to a symmetrical three phase fault in electrical grid, a great number of protective relays provide false trips. Thus, the ability of proposed AFIS scheme to discriminate between faults and heavy loads is a critical issue. Consequently, the FDI is proposed to discriminate between the impacts of fault and heavy load condition. Six different cases are investigated in studied system at G2 as shown in Fig. 4 to evaluate the proposed protection scheme performance. Table 3 illustrates these cases that are relevant to energizing pure resistive (case-1), pure-capacitive (case-2), pure-inductive load (case-3) as 390 MW, 100, 150 MVAR, respectively. Also, 170-j156 MVA and 340-j310 MVA inductive loads (case-4 and case5), respectively, are considered with $195+$ j100 MVA capacitive load (case-6) to assess the proposed scheme. As observed in Tab. 3, the obtained results of proposed scheme involving FDI for heavy load connections exceed the fixed threshold, so the protection scheme avoids false tripping 
Table 3. Simulation studies for energizing heavy loads at G2 in first system with $i_{0}=0$

\begin{tabular}{lccccc}
\hline Loading & $q d_{\mathrm{a}}$ & $q d_{\mathrm{b}}$ & $q d_{\mathrm{c}}$ & $F D I$ & Fault decision \\
\hline Normal load & & & & & \\
$\rightarrow$ & $2.018 \times 10^{3}$ & $2.146 \times 10^{3}$ & $2.184 \times 10^{3}$ & 0.07 & Healthy \\
\hline Case-1 & $2.734 \times 10^{5}$ & $8.126 \times 10^{5}$ & $7.425 \times 10^{5}$ & 0.72 & No fault \\
Case-2 & $1.012 \times 10^{6}$ & $1.460 \times 10^{6}$ & $1.624 \times 10^{6}$ & 0.35 & No fault \\
Case-3 & $4.238 \times 10^{5}$ & $9.644 \times 10^{5}$ & $8.917 \times 10^{5}$ & 0.60 & No fault \\
Case-4 & $2.492 \times 10^{5}$ & $4.712 \times 10^{5}$ & $3.631 \times 10^{5}$ & 0.61 & No fault \\
Case-5 & $2.707 \times 10^{5}$ & $7.256 \times 10^{5}$ & $6.399 \times 10^{5}$ & 0.71 & No fault \\
Case-6 & $2.452 \times 10^{5}$ & $6.819 \times 10^{5}$ & $6.088 \times 10^{5}$ & 0.72 & No fault \\
\hline
\end{tabular}

Table 4. An assessment comparison between the suggested scheme with closed similar schemes in the literature

\begin{tabular}{|c|c|c|c|c|c|c|c|c|}
\hline $\begin{array}{l}\text { Refe- } \\
\text { rence }\end{array}$ & $\begin{array}{l}\text { Signal } \\
\text { type }\end{array}$ & $\begin{array}{c}\text { Feature } \\
\text { recognition } \\
\text { tool }\end{array}$ & $\begin{array}{c}\text { Sampling } \\
\text { rate } \\
(\mathrm{kHz})\end{array}$ & $\begin{array}{c}\text { Data } \\
\text { window } \\
\text { (of cycle) }\end{array}$ & $\begin{array}{l}\text { Network } \\
\text { type }\end{array}$ & $\begin{array}{c}\text { Max fault } \\
\text { resistance } \\
(\Omega)\end{array}$ & $\begin{array}{l}\text { Heavy } \\
\text { load } \\
\text { impact }\end{array}$ & $\begin{array}{c}\text { Source } \\
\text { impedance } \\
\text { impact }\end{array}$ \\
\hline$\overline{[4]}$ & $\bar{I}$ & $\begin{array}{c}\text { DWT,db6 } \\
\text { 1-level }\end{array}$ & 5 to 10 & $1 / 2$ & $\begin{array}{c}400 \mathrm{kV} / 4 \text {-bus, meshed } \\
\text { system }\end{array}$ & 1000 & - & $\begin{array}{c}\checkmark, \pm 10 \% \\
\text { of base value }\end{array}$ \\
\hline$[5]$ & $\mathrm{V}$ & $\begin{array}{c}\text { DWT, db4 } \\
\text { 4-level }\end{array}$ & 5 & $1 / 5$ & $\begin{array}{c}400 \mathrm{kV} / 2 \text {-terminal } \\
\text { system }\end{array}$ & 100 & - & $\begin{array}{c}\checkmark, \text { twice } \\
\text { the base value }\end{array}$ \\
\hline$[6]$ & I & $\begin{array}{l}\text { DWT, bior2.2 } \\
\text { 1-level }\end{array}$ & 6.4 & $1 / 16$ & $\begin{array}{c}500 \mathrm{kV} / 2 \text {-terminal } \\
\text { system }\end{array}$ & 300 & - & $\begin{array}{c}\checkmark,+40 \% \\
\text { of base value }\end{array}$ \\
\hline$[7]$ & I & $\begin{array}{l}\text { DWT, db1 } \\
\text { 1-level }\end{array}$ & 6.4 & 1 & $\begin{array}{c}500 \mathrm{kV} / 2 \text {-terminal } \\
\text { system }\end{array}$ & 50 & - & - \\
\hline$[8]$ & I & $\begin{array}{c}\text { DWT, Haar } \\
\text { 1-level }\end{array}$ & 6.4 & 1 & $\begin{array}{c}500 \mathrm{kV} / \text { multi-terminal } \\
\text { system }\end{array}$ & 100 & - & - \\
\hline$[9]$ & V\&I & $\begin{array}{c}\text { DWT, SVD } \\
\text { 4-level }\end{array}$ & 15.36 & $1 / 4$ & $\begin{array}{l}\text { WSCC/nine-bus } \\
\text { system }\end{array}$ & 40 & - & - \\
\hline$[11]$ & $\begin{array}{l}\text { Reactive } \\
\text { power }\end{array}$ & $\begin{array}{l}\text { DWT, db1 } \\
\text { 1-level }\end{array}$ & 6.4 & $1 / 8$ & $\begin{array}{l}500 \mathrm{kV} / \text { Teed } \\
\text { circuit }\end{array}$ & 600 & - & $\begin{array}{c}\checkmark, \pm 15 \% \\
\text { of base value }\end{array}$ \\
\hline$[14]$ & I & $\begin{array}{c}\text { MWPT, RBFNN } \\
\text { 1-level }\end{array}$ & 10 & 1 & $\begin{array}{c}500 \mathrm{kV} / 2 \text {-terminal } \\
\text { systemt }\end{array}$ & 300 & - & - \\
\hline$[16]$ & I & ITD, SVD, PNN & 1.2 & $1 / 2$ & $\begin{array}{c}500 \mathrm{kV} / 3 \text {-source } \\
\text { systemt }\end{array}$ & 130 & - & - \\
\hline$[25]$ & V\&I & $\begin{array}{c}\text { WT } \\
\text { norm entropy }\end{array}$ & 8 & $1-$ & $\begin{array}{l}400 \mathrm{kV} / \text { compensated } \\
\text { 2-terminal system }\end{array}$ & - & - & - \\
\hline \multicolumn{9}{|c|}{ Proposed in this work } \\
\hline & $\begin{array}{l}\text { Reactive } \\
\text { power }\end{array}$ & $\begin{array}{l}\text { DWT, db6 } \\
\text { 1-level }\end{array}$ & 6.4 & $1 / 16$ & $\begin{array}{c}500 \mathrm{kV} \\
\text { compensated grid }\end{array}$ & - & $\checkmark$ & $\checkmark$ \\
\hline
\end{tabular}

\section{Assessment study of fault identification scheme}

An assessment study has been addressed to evaluate and compare the suggested scheme with other similar schemes in the survey. The data is classified according to required signal type, feature recognition tools, sampling rate used, network configuration type, maximum fault resistance, heavy load impact, source impedance variation as well. The performance of the proposed scheme is assessed with existing fault identification schemes which applied to the compensated network configurations as can be seen in Tab. 4. 
The main gap in the existing schemes is that they have not dealt with the impact of heavy load switching while the proposed scheme is validated to this issue. The proposed scheme has capability to discriminate between the fault and heavy load condition without any false tripping in the almost test cases. Further, the proposed study is only based on the reactive power measurements corresponding to three phases during disturbance whether healthy disturbance or unhealthy disturbance. Using reactive power measurements as input signals can cope with high fault resistance, this issue uncovered in $[5,7,9$, and 25]. This is right because it works with reactive power measurements (Q) during faults, which is based on the production of current and voltage signals for their computation. It is well-known that the greater fault current is accompanied by the less voltage and vice versa. Despite methods based PNN and RBFNN as in [15, 17] are quite successful in fault identification task, the main gab of these studies is that they require a huge amount of training effort for high performance. On the other hand, the proposed scheme does not require any artificial classifier technique, it based on only the logic flow concept. It is observed that the proposed scheme has fast response as shown in Tab. 4 it needs only $1 / 16$ of cycle data window to make final decision.

\section{Conclusions}

In this study, the adaptive fault-identification relay was proposed to discriminate between heavy load switching and fault occurrence on transmission lines. Based on the influence of reactive-power behaviour during faults, the proposed scheme could detect and classify short circuit faults for compensated transmission network correctly. The details wavelet coefficients with one-level of decomposition were employed to recognition the empirical fault scenarios on transmission network. The proposed technique was dependent on the adaptive threshold value that was estimated according to the correlative concept among the sum of details coefficient based on reactive power computations corresponding to three phases. The key factors that inuence the analysis of the transients produced as the fault occurrence were considered. Moreover, the reliability of the proposed scheme with healthy disturbance was also tested by varying load changing, source impedances. In addition, the response of proposed scheme based on dependability and security were discussed and the obtained results showed that the proposed AFIS has a good performance. The effects of series compensated transmission line were evaluated under different compensation levels. It was observed from simulation results that the proposed method was able to detect and classify faults at different fault scenarios. The analysis results indicated that the proposed approach achieves satisfactory performance with a low misdetection rate and an acceptable reaction speed to fault.

\section{REFERENCES}

[1] Y. Usama, X. Lu, H. Imam, et al, "Design and implementation of a wavelet analysis-based shunt fault detection and identification module for transmission lines application", IET Generation, Transmission \& Distribution, vol. 8, no. 3, pp. 431-441, 2013.

[2] H. A. Darwish, M. Hesham, A.-M. I. Taalab, et al, "Close accord on DWT performance and real-time implementation for protection applications", IEEE Transactions on Power Delivery, vol. 25, no. 4, pp. 2174-2183, 2010.

[3] A. R. Adly, R. A. El Sehiemy, and A. Y. Abdelaziz, "A negative sequence superimposed pilot protection technique during single pole tripping", Electric Power Systems Research, vol. 137, pp. $175-189,2016$

[4] S. P. Valsan and K. S. Swarup, "Fault detection and classification logic for transmission lines using multi-resolution wavelet analysis", Electric Power Components and Systems, vol. 32, no. 4 , (2008): 321-344.

[5] O. A. S. Youssef, "New algorithm to phase selection based on wavelet transforms", IEEE transactions on Power Delivery, vol. 17 , no. 4, pp. 908-914, 2002

[6] A. R. Adly, R. A. El Sehiemy, and A. Y. Abdelaziz, "A novel single end measuring system based fast identification scheme for transmission line faults", Measurement, vol. 103, pp. 263-274.

[7] A. R. Adly, R. A. El Sehiemy, and A. Y. Abdelaziz, "Critical aspects on wavelet transforms based fault identification procedures in HV transmission line", IET Generation, Transmission \& Distribution, vol. 10 no. 2, pp. 508-517, 2016.

[8] M. I. Zaki, R. A. El Sehiemy, G. M. Amer, et al, "Integrated Discrete Wavelet Transform-Based Faulted Phase Identification for Multi- Power Systems Nineteenth International Middle East Power Systems Conference, (MEPCON), 2017.

[9] D. Guillen, M. R. A. Paternina, A. Zamora, et al, "Detection and classification of faults in transmission lines using the maximum wavelet singular value and Euclidean norm", IET Generation, Transmission \& Distribution, vol. 9, no. 15, pp. 2294-2302, 2015.

[10] Z. He, L. Fu, S. Lin, and Z. Bo, "Fault detection and classification in EHV transmission line based on wavelet singular entropy", IEEE transactions on Power Delivery, vol. 25, no. 4, pp. 2156-2163, 2010.

[11] M. I. Zaki, R. A. El-Sehiemy, G. M. Amer, et al, "An investigated reactive power measurements-based fault-identification scheme for teed transmission lines. ",Measurement, vol. 136, pp. $185-200,2019$

[12] M. I. Zaki, R. A. El Sehiemy, G. M. Amer, et al, "Sensitive/stable complementary fault identification scheme for overhead transmission lines",IET Gen Trans. \& Dist, vol. 13, no. 15, pp. 3252-3263, 2019.

13] K. M. Silva, B. A. Souza, and N. S. D. Brito, "Fault detection and classification in transmission lines based on wavelet transform and ANN", IEEE Transactions on Power Delivery, vol. 21, no. 4, pp. 2058-2063, 2006.

[14] S. R. Samantaray, P. K. Dash, and G. Panda, "Fault classification and location using HS-transform and radial basis function neural network", Electric Power Systems Research, vol. 76, no. 9, pp. $897-905,2006$

15] H. Zheng-you, C. Xiaoqing, and F. Ling, "Multi-wavelet packet entropy and its application in transmission line fault recognition and classification", IEEE transactions on neural networks and learning systems, vol. 25, no. 11, pp. 2043-2052, 2014.

16] J. Upendar, C. P. Gupta, and G. K. Singh, "Discrete wavelet transform and probabilistic neural network-based algorithm for classification of fault on transmission systems", India Conference, INDICON 2008, Annual IEEE. , 2008.

[17] M. Pazoki, "A New Fault Classifier in Transmission Lines Using Intrinsic Time Decomposition", IEEE Transactions on Industrial Informatics, vol. 14, no. 2, pp. 619-628, 2018. 
[18] M. Mirzaei, B. Vahidi, and S. H. Hosseinian, "Fault location on a series-compensated three-terminal transmission line using deep neural networks", IET Science, Measurement \& Technology, vol. 12, no. 6, pp. 746-754, 2018.

[19] A. A. Yusuff, A. A. Jimoh, and J. L. Munda, "Determinant-based feature extraction for fault detection and classification for power transmission lines", IET generation, transmission \& distribution, vol. 5, no. 12, pp. 1259-1267, 2011.

[20] B. Bhalja and R. P. Maheshwari, "Wavelet-based fault classification scheme for a transmission line using a support vector machine", Electric Power Components and Systems, vol. 36, no. 10, pp. 1017-1030, 2008.

[21] B. Vyas, R. P. Maheshwari, and B. Das, "Protection of series compensated transmission line: issues and state of art", Electric power systems research, 107, pp. 93-108, 2014.

[22] N. Kang, J. Chen, and Y. Liao, "A fault-location algorithm for series-compensated double-circuit transmission lines using the distributed parameter line model", IEEE Transactions on Power Delivery, vol. 30, no. 1, pp. 360-367, 2015.

[23] A. R. Adly, R. A. El Sehiemy, and A. Y. Abdelaziz, "A directional protection scheme during single pole tripping ", Electric Power Systems Research, vol. 144, pp. 197-207, 2017.

[24] A. R. Adly, R. A. El Sehiemy, and A. Y. Abdelaziz et al, "An accurate technique for discrimination between transient and permanent faults in transmission Terminals networks ", Electric power components and systems, vol. 45, no. 4, pp. 366-381, 2017.

[25] X. Luo, C. Huang, Y. Jiang, et al, "An adaptive three-phase reclosure scheme for shunt reactor-compensated transmission lines based on the change of current spectrum", Electric Power Systems Research, vol. 158, pp. 184-194, 2018.

[26] H. Eristi, "Fault diagnosis system for series compensated transmission line based on wavelet transform and adaptive neuro-fuzzy inference system", Measurement, vol. 46, no. 1, pp. 393-401, 2013.

[27] H. Akagi, Y. Kanazawa, and A. Nabae, "Instantaneous reactive power compensators comprising switching devices without energy storage components", IEEE Transactions on industry applications, , vol. 3, pp. 625-630, 1984.

[28] S. P. Valsan and K. S. Swarup, "Wavelet transform based digital protection for transmission lines ", International Journal of Electrical Power \& Energy Systems, vol. 31, no. 7-8, pp. 379-388, 2009.

[29] B. Jain, S. Jain and R. K. Nema, "Investigations on power quality disturbances using discrete wavelet transform", International Journal of Electrical, Electronics and Computer Engineering, vol. 2, no. 2, pp. 47-53, 2013.

[30] V. K. Gaur and B. Bhalja, "A new faulty section identification and fault localization technique for three-terminal transmission line", International Journal of Electrical Power \& Energy Systems, vol. 93 pp. 216-227, 2017.

[31] Z. He, L. Fu, S. Lin, et al, "Fault detection and classification in EHV transmission line based on wavelet singular entropy", IEEE transactions on Power Delivery, vol. 25, no. 4, pp. 2156-2163, 2010 .

Received 11 January 2021

Mohamed I. Zaki currently works as Assistant Lecturer at the Department of Electric Power and Machines, Benha University, Egypt. He received his MSc at Benha Faculty of Engineering-Benha University in 2019. He also received his BSc at Benha faculty of engineering in 2015. Main research topics are in Wide-Area Backup Protection in Power Systems with High Penetration of Renewable Energy Sources and Protection and analysis of power system with applications to the transmission and distribution system. His most recent publications are on time-frequency domain protection elements-based fault Identification algorithms.

Ragab A. El-Sehiemy, Senior Member IEEE, was born in Menoufia, Egypt, in 1973. He received the BSc, Msc and PhD degrees from Menoufia University, Egypt, in 1996, 2005, and 2008, respectively. $\mathrm{He}$ is currently Professor with the Electrical Engineering Department, Faculty of Engineering, Kafrelsheikh University, Egypt. He received Prof. Mahmoud Khalifia Award in Power System Engineering from Academy of research and technology in 2016. He is the receipt of ElShorouk Academy for computers and information in industry from Academy of research and technology in 2021. He is an Editor of International Journal of Engineering Research in Africa and an Associate Editor in IEEE Access. Professor ElSehiemy has more than 150 articles in peer review journals and conferences His research interests include smart grid and its applications, optimization and AI, and its application to power systems. Renewable energies, power systems protection.

Ghada Amer (Prof) is Vice Dean for Postgraduate Studies and Research Faculty of Engineering Benha University, the President of Centre for Strategic Studies of Science and Technology, and V. P. at Arab Science and Technology Foundation. She holds few more positions within her profession, like the Director of Innovation and Entrepreneurship Centre at Benha University, the CEO and the Co-founder of ASTF innovation Lab, the ex-Head of Electrical Engineering Department at Benha University and the CEO of the Global Awqaf Research Centre. Because she believes on the important of R\&D and innovation for community, she selected in 2016 to be one of the Rolex Enterprise Awards for Innovation Jury members. She was names in Jan 2014 as one of Top 20 Influential Muslim Women Scientist in the World, by on Muslim-Science Magazine. And named as the "Personality of the Year", 